classes of analyst ; for example, Vol. I contains papers on the analysis of coal and of plating and gilding solutions, as well as much work on various foods. Each volume is available separately from any bookseller or direct from the publishers at 6 guineas, bound in cloth boards in the style of the original. Publication in America is through the Johnson Reprint Corporation.

\section{The Wellcome Museum of Medical Science}

SrNCE it was opened by the Wellcome Foundation in 1914, the Wellcome Museum of Medical Science in Euston Road, London, has provided a unique display of photographs, specimens and extracts from medical literature, which give, in study units housed in comfortable and attractive bays screened off from the rest of the Museum, comprehensive information about each of the diseases dealt with (see "The Wellcome Museum of Medical Science". Pp. 40. London: The Wellcome Foundation, Ltd., 1958). Some 10,000 doctors, nurses, medical missionaries and students visit the Museum each year from all parts of the world. Originally the Museum was devoted largely to tropical diseases, but nowadays it covers a much wider field. Recently reorganized, it now reflects the changes in emphasis on certain diseases which have resulted from the remarkable advances in control and treatment that have been made in recent years. Thus, the thirty-two panels formerly given to syphilis have now been reduced to four, and the seven panels given earlier to plague have been reduced to three. Cholera also is no longer feared as it used to be. Malaria, however, still occupies forty-two panels, though if the schemes for its control and eradication continue to succeed as they have done during the past five years, much less space will be needed to cover this disease, which has for long been the greatest single cause of illness and death in the world. Tuberculosis, on the other hand, is likely to be given more space to illustrate its importance in the tropics. A pleasing feature of the Museum's activities is the use that is made of it by boys' and girls' schools, to which the Museum lends suitable selections of material for the stimulation of interest in biology. It also lends or gives exhibits to medical schools throughout the Commonwealth. Last year a section of the Museum was shown in Durban, South Africa, and another section, devoted to trypanosomiasis in Africa and South America, was shown at the sixth International Congress on Tropical Medicine and Malaria at Lisbon.

\section{Systematics of Parrot-fishes}

ThE brightly coloured parrot-fishes are ubiquitous denizens of coral reefs throughout the tropics. For feeding on coral the dentition has been greatly modified, with fusion of the teeth in the front of the jaws into a pair of dental plates forming the 'parrot's beak' from which these fish get their name. The pharyngeal musculature is highly developed and operates a mill formed of grinding teeth on the pharyngeal bones. Many of the species have a large swelling on the forehead which adds to their bizarre appearance. In the past, the systematic description of this group has been highly confused and more than 350 species have been named and described. In a recent publication (U.S. National Museum, Bulletin 214: Review of the Parrotfishes, Family Scaridae, by L. P. Schultz. Pp. v+143+27 plates. Washington, D.C. : Government Printing Office, 1958. 75 cents), the curator of fishes of the United States National
Museum has done much to unravel the confused systematics of the parrot-fishes. He claims that only eighty species can be regarded as valid. Many of the large number described, he points out, have been erected into so-called species on the basis of colour patterns which vary not only between individuals but between different stages in the life-history of one individual, while there is also a sexual dichromatism. His review of the Scaridae at last places this family in some sort of perspective and demonstrates their relationship with the labrid fishes. There are excellent keys to genera and species.

\section{Dormancy in Viburnum Seeds}

IN an investigation of dormancy in the seeds of Viburnum trilobum, R. H. Knowles and S. Zalik (Canadian J. Bot., 36, 561 ; 1958) have observed this phenomenon in seedlings as well as in seeds. When seeds were maintained at $20^{\circ} \mathrm{C}$. under suitable conditions for germination, there was slow growth in the radicle and hypocotyl in some seeds, while others showed no response. They have found that this kind of dormancy is associated with the presence of a water-soluble inhibitor in the endocarp and with the need for an appropriate (inductive) temperature treatment prior to exposure to a constant $20^{\circ} \mathrm{C}$.; they also found that dormancy in the epicotyl, namely, failure of shoot growth in the young seedling, could be overcome by removing the cotyledons.

\section{Tropical Karst}

LANDFORMS developed in regions of massive limestone or dolomite where erosion is principally by solution of the rock rather than mechanical corrasion have long been known as 'karst' from the area in Yugoslavia where they were first investigated. The karstlands of temperate latitudes have received considerable attention, but their occurrence in tropical areas has been less closely studied. In an article in the Geographical Journal (124, part 2, 184; June 1958) Dr. Marjorie Sweeting gives an admirably lucid account of its distribution and characteristics in Jamaica. She shows that even in an area of pure, free-draining limestone an annual rainfall of $100 \mathrm{in.}$ or more is sufficient to maintain a heavy forest cover and that water passing through this cover is so highly charged with organic carbon dioxide that the solution rates may be 400 per cent greater than in cooler climates. The most characteristic land-form produced under these conditions is 'cockpit karst', in which the entire surface is covered by conical depressions, here. $300-400 \mathrm{ft}$. deep, separated by cone-like hills. There are no watercourses on the surface. Where the crystalline white limestone passes into other formations and free vertical drainage is checked, solution and sapping takes place along the base and sides of the cockpits and the mechanical effect of flood water in undercutting and steepening the sides is considerable, and 'tower karst' develops. Dr. Sweeting indicates that in areas of more marly limestone and lower rainfall dolines and poljes, already well known from European examples, develop. She gives some attention also to associated caves and underground river systems.

\section{Mond Nickel Fellowships}

THE Mond Nickel Fellowships Committee recently announced the award of fellowships for 1958 to the following: Mr. G. H. Longworth (Lancashire Steel Manufacturing Co., Ltd.) to study the manufacture of plain carbon and alloy steels for rod and wire 